\title{
REGIONAL TEXT IN MODERN SOCIO-CULTURAL DYNAMICS
}

\author{
Viktoria A. Khrapova \\ Volgograd State University, Volgograd, Russian Federation \\ Ivan V. Karandashov \\ Volgograd, Russian Federation
}

\begin{abstract}
In the modern globalizing transforming world, regionalization processes are intensifying. Selfdetermination of the region is associated with the development of viable programs of socio-economic development. Important components of such a program can be concentrated in the regional text, which reflects the communicative specificity of regional everyday life and the nature of the interrelationships of the regional community with the outside world. Modern regional text is in its infancy. Fixing the key components of a regional culture as a form of being of a person and society established in certain space-time coordinates, it assumes a constant interpretation, undergoes deconstruction in accordance with the changes that occur at the state level and the world as a whole. In the conditions of modern transformation, well-organized communication strategies are of great importance in bifurcation points. It is obvious that such strategies should take into account the interests of the individual and society and should not contradict the general civilization processes. Regional texts carry the idea of organic integrity, unity of nature, man and society.This makes them popular in today's dynamic, unstable social space. However, the cognitive context of using locally rooted texts is expanding. Metaphorizing the world, they create ample opportunities for translocal identities. Keeping the identification potential of local texts, the regional text is open to innovation. In the modern risk-taking social space, it is important to develop a system of values aimed, first and foremost, at achieving human and social security. According to the authors of the article, this goal can be achieved provided the regional community understands the unique value of the local identity, as well as the geopolitical role and socio-economic functions of the region on a nationwide scale. The regional text as a set of cultural constants, fixed by the public consciousness as a significant semantic and ideological complex, has great potential that needs to be developed in order to optimize the existence of man and society.
\end{abstract}

Key words: region, culture, text, communication, sociocultural dynamics.

УДК $316: 366.632$

ББК 60.524 .224

\section{РЕГИОНАЛЬНЫЙ ТЕКСТ В СОВРЕМЕННОЙ СОЦИОКУЛЬТУРНОЙ ДИНАМИКЕ}

\author{
Виктория Анатольевна Храпова \\ Волгоградский государственный университет, г. Волгоград, Российская Федерация
}

Иван Вадимович Карандашов

г. Волгоград, Российская Федерация

Аннотация. В современном глобализирующемся и трансформирующемся мире усиливаются процессы регионализации. Самоопределение региона связано с выработкой жизнеспособных программ социально-экономического развития. Их важные составляющие могут быть сконцентрированы в региональном тексте, отражающем коммуникативную специфику региональной повседневности и характер взаимосвязей регионального сообщества с внешним миром. Современный региональный текст находится в стадии становления. Фиксируя ключевые компоненты региональной культуры как сложившейся в определенных про- 
странственно-временных координатах формы бытия человека и общества, он предполагает постоянную интерпретацию, подвергается деконструкции в соответствии с теми изменениями, которые происходят на государственном уровне и в мире в целом. В условиях современной трансформации, точках бифуркации, большое значение имеют хорошо организованные коммуникативные стратегии. Очевидно, что последние должны учитывать интересы человека и общества и не противоречить общецивилизационным процессам. Региональные тексты несут в себе идею органичной целостности, единства природы, человека и общества. Это делает их востребованными и популярными в современном динамичном и неустойчивом социальном пространстве. Однако расширяется когнитивный контекст использования локально укорененных текстов. Метафоризируя мир, они открывают широкие возможности для создания транслокальных идентичностей. Сохраняя в себе идентификационный потенциал локального текста, региональный текст открыт для инноваций. В современном рискогенном социальном пространстве важно выработать систему ценностей, направленных, в первую очередь, на достижение безопасности человека и общества. Как представляется авторам статьи, эта цель может быть достигнута при условии понимания региональным сообществом уникальной ценности локального своеобразия, а также геополитической роли и социально-экономических функций региона в общегосударственном масштабе. Региональный текст как совокупность культурных констант, фиксируемых общественным сознанием в качестве значимого семантического и идеологического комплекса, обладает большим потенциалом, который необходимо развивать в целях оптимизации бытия человека и общества.

Ключевые слова: регион, культура, текст, коммуникация, социокультурная динамика.

Усиление процессов регионализации в современном трансформирующемся и глобализирующемся мире имеет своим следствием самоопределение региональных общностей, обязательным условием которого является выработка жизнеспособных программ социально-экономического и политического развития. Становление региона как геополитической единицы, обладающей определенным статусом в системе общественных отношений, связано также с формированием региональной культуры как исторически складывающейся в определенных пространственно-временных координатах формы бытия социума и человека, которая имеет свою систему ценностей и продуцирует особый тип личности [7]. Важнейшим элементом региональной культуры становится региональный текст, аккумулирующий в себе систему ключевых для данной культуры значений и реконструирующий черты образа региона в процессе социальной коммуникации. Формирование регионального текста является важным этапом самоопределения региона, характеризует его состояние в настоящем и предопределяет позицию в будущем.

С начала 90-х гг. XX в. в связи с развитием центробежных тенденций усилился интерес к изучению локальных текстов культуры. В процессе длительного исторического развития общества на определенной территории формируются устойчивые концепты, свидетельствующие о фрагментации мира, спе- цифике его видения, характере отношения людей к выделяемой части пространства. Их семантика формируется краеведческими исследованиями в процессе осмысления визуальных образов среды посредством художественного осмысления природного ландшафта. В семантическом поле этих концептов присутствует инвариант, выполняющий роль идентификационного кода местности. Совокупность концептов, представленная в разных дискурсах, образует особый сверхтекст, транслирующий информацию, позволяющую идентифицировать локальное пространство, актуализировать связанные с ним ассоциации. По мнению большинства исследователей, содержание локального текста складывается вокруг определенного мифа-символа - закодированной в метафорической форме легенды или истории о специфике данного места, охраняющих его духах и героях, о влиянии территории на человека.

Согласно концепции, предлагаемой С. Агранович и И. Саморуковой, миф - среда обитания нашего сознания, специфически человеческий способ творения (моделирования мира) и тем самым освоения и познания реальности, некий универсальный образ мира. По законам мифа человек выстраивает отношения с миром, соблюдая правила взаимодействия, сложившиеся в ту или иную эпоху. Смена эпох, а значит, смена экономических, социальных и культурных условий жизни человека - всегда смена мифов. 
Структура мифологического сознания видится исследователями в виде триады «Субъект - Объект - Абсолют», где Субъект человек со всеми вопросами и проблемами, задачами и эмоциями - существо уязвимое, с обостренным восприятием действительности, каждой ее минуты, с постоянной оценкой себя, с неудовлетворенностью своей деятельностью. Объект - это мир, в котором живет человек, явления, происходящие в этом мире, реакции людей на события окружающей действительности независимо от масштаба происходящего. Абсолют - мера всех вещей в данную эпоху и в то же время волшебный помощник человека в его отношениях с объектом, медиативное образование как высшее знание, определяющее отношения субъектов и объектов, универсальная ценность данного периода. История любого народа складывается из движения к тому или иному Абсолюту. Этому движению подчиняется все - политика, экономика, наука, семья.

Триада представляет собой динамический механизм, который реализуется в социальных и художественных процессах, являясь основой генетического кода культуры.

С. Агранович и И. Саморукова выделили два типа культуры: культуру гармонии, которая сформировалась на базе архаического мифа и до личностного сознания, и культуру цели, связанную с формированием монотеизма и идеи трансцендентной личности. Культура цели подразумевает необходимость напряжения воли, насилие над естественным ходом вещей. Но, вырастая из культуры гармонии в результате перекодировки языка последней, она также содержит в имплицитной форме идею гармонии. Исследователи констатируют, что после культуры цели начинает формироваться культура образа-концепта, которая предполагает диалог между земной гармонией и трансцендентной целью.

Современный этап общественного развития соответствует состоянию, когда культура цели, исчерпав себя, подходит к логическому завершению. Триада распадается, образуется ценностная пустота. Все мы бродим в поисках кода, предощущая «нечто, что будет нами осознано, когда мы выйдем из мифа, который нам еще не предложен» [1, с. 9]. Универсальным ритуалом нашего времени ста- новится коммуникация, главной медиативной ценностью - язык. Человек ведет диалог с языком, в котором играют гены всех культурных эпох и народов [1].

Рубеж тысячелетий совпал с началом глобальной трансформации всех сфер жизни человека и общества. Переходные этапы сопровождаются изменением картины мира. В такие периоды происходит взрыв эсхатологических настроений, кризис коллективной идентичности, рост интереса к архетипу и мифу как нарративной структуре, в которой сконцентрированы представления о фундаментальных основах бытия. Но для современного модернизирующегося общества важны не объяснительный потенциал и не идентификационная сила локального текста, а заложенная в нем идея органичного начала, естественной связи и целостности человека, природы и общества. Реактивируемая в любом социальном контексте, эта идея придает устойчивость любым социальным программам и политическим манифестациям.

Локальный текст является носителем традиционной культуры, происхождение которой всегда территориально обусловлено и связано с возникновением представлений о сакральном центре, определяющем характер ценностей. Бытие этого текста связано с его способностью нести в себе определенную картину мира, определенный взгляд на мир, укорененный в некоем локальном мифе. Миф модерна совмещает сакральное и профанное. Он открыт, находится в стадии становления. В связи с этим интересны заметки А. Флиеpa, который пишет: «Если ранее локальная специфичность культуры являлась самодовлеющей и была основана на устойчивом обычае (бытовых традициях, языке, религии), то постепенно культурная специфичность становится ситуативной и основывается преимущественно на актуальном интересе (как правило, политическом или экономическом). Кроме того, наблюдается более или менее выраженная несовместимость локальной специфичности и ускорения динамики социального развития. Устойчивость культурной специфичности обеспечивалась замедленными темпами развития общества. При динамизации социального развития в жертву ему, как показывают многочисленные исторические приме- 
ры, приносится, прежде всего, заметная часть традиционной культурной специфики этого общества. Можно даже утверждать, что локальные культуры сообществ, находящихся на одной стадии развития, по мере перехода от одной исторической эпохи к другой становятся все менее специфичными по отношению друг к другу. Причем, чем больше ускоряется темп социального развития, тем быстрее утрачиваются признаки локального культурного своеобразия, приносимого в жертву темпам социального развития» [9, с. 89].

В условиях современной социальной трансформации, как пишет Д. Замятин, «пространство локальных мифов начинает быстро расширяться не в смысле хорошо известной специалистам повторяемости базовых архетипических сюжетов, воспроизводящихся в совершенно разных цивилизациях и культурах и на сильно удаленных друг от друга территориях, в совершенно различных порой природных и культурных ландшафтах, а в смысле их семантической и образной экспансии в ранее не достижимые для них области ментальной и материальной жизни региональных сообществ» [4].

Исследователь отмечает, что в эпоху модерна изменились когнитивные контексты развития и функционирования локальных мифов. Они стали «восприниматься, воображаться, конструироваться и деконструироваться в рамках целенаправленных актов сознания, стремящихся к оконтуриванию, фиксации оригинальных метагеографических пространств с целью маркетинга территорий и мест в социокультурном проектировании, образно-географическом проектировании, стратегическом планировании и брендинге территорий, региональном политологическом анализе и т. д.» [4]. Региональный текст используется как нарратив, поддерживающий весь комплекс «установок» и практик, соответствующих новому этапу исторического развития. «Локальные мифы оказываются не только традиционными ментальными нарративами, описывающими и характеризующими определенные места и территории, но и принципиально, жизненно, экзистенциально важными компонентами видения не только прошлого и настоящего, а также и будущего - будущее начинает как бы закрепляться, “фиксироваться” соответствующими легендарными событиями и историями, уверенно проецируемыми в пространство еще не сбывшегося, не состоявшегося, однако весьма возможного и желательного» [4].

Коммуникация - универсальная технология, обеспечивающая становление социума. Коммуникативные процессы воспроизводят традицию и способствуют обновлению культуры, обуславливают развитие личности и предполагают необходимость самореализации.

Процесс коммуникативного творчества происходит по законам свободной самоорганизации, включающей в себя рефлексивную и практическую деятельность человека. Как известно, К. Лоренц, используя термин «креативные вспышки», описал возникновение новых системных свойств в ходе эволюции. В процессе мышления, специфическим образом выстраивающегося в современном социокультурном контексте, происходит не просто объединение в целое частей, их самоструктурирование, а «вырастание» целого в результате самоусложнения частей. Поток мыслей, образов усложняется и спонтанно организуется определенным образом. Знаки обретают новые значения и смыслы, приводящие к возникновению новых связей и новых структур. «“Блуждания по полю возможных путей развития", хаотическая активность креативного разума периодически приводят к “выпадению” на ту или иную структуру-аттрактор» [5, с. 139]. То есть одна из возможных, пока непроявленных структур актуализируется и происходит кристаллизация нового знания. Описываемое явление получило в современной науке название «аутопоэзис», выражающее способность живых систем самообновляться в процессе функционирования. Уникальной системой, позволяющей наблюдать аутопоэзис, является язык, который, описывая мир, включает в себя рефлексию, предполагает осмысление и осознавание настоящего в контексте перспектив будущего.

Региональный текст - сверхсложная динамическая система. Генезис регионального текста происходит в среде, в которой образуется нераздельное скопление семантических структур, средоточие семантических центров различных социальных и культурных систем. Синергетическая методология позволяет наблюдать органичность самоорганизации реги- 
онального текста как целостной формы, обретающей новые элементы в процессе эволюции в едином процессе с окружающей средой и включенным в нее человеком.

Для всего научного сообщества рубеж тысячелетий стал периодом осмысления пограничных маргинальных состояний, рубежных отношений, коммуникации. На основании многочисленных исследований был сделан вывод о том, что зоны взаимодействия природных, экономических, этнокультурных, информационных и других полей становятся источниками креативности, усиления энергетики. В периоды трансформации возрастает роль мыслящих и обладающих волей субъектов, сознательный выбор которых становится объективным фактором исторического процесса [10]. Родина во многом определяет судьбу, а время, историческая ситуация - меру ответственности. В атмосфере, стимулирующей творческие потенции, в точке бифуркации, самый, казалось бы, незначительный элемент может определить выбор исторического пути. В такие периоды слово, речь приобретают важное историческое значение [10].

Современный региональный текст несет в себе устойчивую систему смыслов и предполагает активную интерпретацию, сотворчество, инновационен по своей природе. Транслируемый им образ региона сегодня - результат преобразования регионального пространства и видения современными людьми доставшегося им от прошлых поколений культурного наследия, а также прообраз будущего состояния. Он является одновременно продуктом и результатом видения ключевых ценностей, на основе которых происходит самоопределение региона в соответствии с избранными целями и средствами социально-экономического развития.

В условиях современной социальной трансформации, сопровождающейся снижением значимости традиционных ценностей, перспективным представляется подход, предложенный Т. Рулиной, которая считает, что нужно искусственно создавать новые области, сферы труда с новыми ценностями, обусловливающими социальную активность, востребованную новыми условиями. Это возможно, так как на додискурсивном уровне существует полисемия смысла [8].
Метафоризируя мир, «локальные мифологии модерна не создают единого метапространства, но способствуют развитию, разрастанию новых семантик возможных миров, способствуя транслокализации, обнаруживая основания для создания общемирового общекультурного пространства. Тем самым метафоризация пространства на основе конкретной топонимики может стать ментальным и онтологическим фундаментом трансрегиональных идентичностей, создающих новый мировой культурный ландшафт» [3, с. 38 ].

В условиях, когда знание, призванное быть гарантом онтологической стабильности, уже не абсолютный, а относительный итог процесса познания, характеризуется нелинейностью, многоплановостью, находится в состоянии фальсификации, неопределенности, имеет рискогенные свойства, а любая ценность должна выдерживать конкуренцию, особенно остро встает вопрос о надежной информации, обеспечивающей безопасность человека и общества.

Многополярный мир нуждается в собственной системе ценностей. Какими они должны быть? Какие ценности в современном мире должен транслировать региональный текст? С нашей точки зрения, специфика ценностей определяется позицией региона, пониманием его жителями того, что региональное самоопределение предполагает встроенность региона в целостность государства. Региональное возрождение - не парад суверенитетов. Местническая идеология ни к чему не ведет, сегодня нужно уметь устанавливать контакты, договариваться о сотрудничестве и взаимопомощи. В этом плане интересны наблюдения писателя-журналиста П. Вайля, отражающие специфику русской ментальности: «Русские путевые заметки эмоцию явно предпочитают информации. Русский путешественник видит то, что он хочет видеть, а перед его умственным взором всегда одна страна - родина» [2, с. 218]. А также замечание филолога-текстоведа А.П. Люсого: «“Текстуальная революция" в России отличается от региональных исследований на Западе тем, что каждый региональный текст представляет собой не какую-то сугубо региональную точку зрения, а попытку концептуального “выворачивания” всей России через себя» [6]. 
Таким образом, региональный текст представляет собой уникальный конструкт, в основу которого заложена совокупность закрепленных традицией, прошедших практику языковых коммуникаций, устойчивых значений, которые спонтанно собираются или рекомбинируются в зависимости от тех целей, которые ставятся человеком и обществом. Для регионального сообщества региональный текст становится своеобразной программой, с одной стороны, обеспечивающей жизнеспособность и устойчивость, с другой - требующей постоянного развития в соответствии с тенденциями общественного развития.

\section{СПИСОК ЛИТЕРАТУРЫ}

1. Агранович, С. 3. Гармония - цель - гармония. Художественное сознание в зеркале притчи / С. З. Агранович, И. В. Саморукова. - М. : Междунар. ин-т семьи и собственности, 1997. $134 \mathrm{c}$.

2. Вайль, П. Гений места / П. Вайль. - М. : Corpus, 2015. $-448 \mathrm{c}$.

3. Замятин, Д. Н. Гуманитарная география: пространство, воображение и взаимодействие современных гуманитарных наук / Д. Н. Замятин // Социологическое обозрение. - 2010. - Т. 9, № 3.C. $26-50$.

4. Замятин, Д. Н. Локальные мифы и географическое воображение / Д. Н. Замятин. - Электрон. текстовые дан. - Режим доступа: http:// www.intelros.ru/subject/figures/dmitriy-zamyatin/ print:page, 1,12250-lokalnye-mify-modern-igeograficheskoe-voobrazhenie.html (дата обращения: 10.09.2018). - Загл. с экрана.

5. Князева, Е. Н. Баланс на краю хаоса/Е. Н. Князева // Синергетическая парадигма. Человек и общество в условиях нестабильности. - М. : Прогресс-Традиция, 2003.- С. 139-143.

6. Люсый, А. П. География текстуальной революции: междисциплинарные исследования локальных текстов культуры / А. П. Люсый // Человек: образ и сущность. - 2014. - № 1. - С. 214-236.

7. Мурзина, И. Я. Региональная культура как предмет философско-культурологического исследования / И. Я. Мурзина // Известия Уральского государственного университета. Проблемы образования, науки и культуры. Вып. 15. - 2003. - № 29. - С. 60-78.

8. Рулина, Т. К. Ментальные подходы к фасилитации больших социальных групп: проблема безопасности коллективного интеллекта сообщества / Т. К. Рулина // Азимут научных исследований. 2015. - № 3 (12) - C. 52-55.
9. Флиер, А. Я. Вектор культурной эволюции / А. Я. Флиер // Обсерватория культуры. - 2011. № 5. - C. 6-18.

10. Храпова, В. А. К вопросу о региональной идентичности / В. А. Храпова // Вестник Волгоградского государственного университета. Серия 7, Философия. Социология и социальные технологии. 2011. - №2 (14). - С. 90-96.

\section{REFERENCES}

1. Agranovich S.Z., Samorukova I.V. Garmoniyatsel-garmoniya. Khudozhestvennoe soznanie v zerkale pritchi [Harmony - Goal - Harmony. Artistic Consciousness in the Mirror of the Parable]. Moscow, Mezhdunar. in-t semyi i sobstvennosti, 1997. $134 \mathrm{p}$.

2. Vayl P. Geniy mesta [The Genius of the Place]. Moscow, Corpus Publ., 2015. 448 p.

3. Zamyatin D.N. Gumanitarnaya geografiya: prostranstvo, voobrazhenie i vzaimodeystvie sovremennykh gumanitarnykh nauk [Humanities Geography: Space, Imagination and Interaction of Modern Humanities]. Sotsiologicheskoe obozrenie, 2010, vol. 9, no. 3, pp. 26-50.

4. Zamyatin D.N. Lokalnye mify $i$ geograficheskoe voobrazhenie [Local Myths and Geographical Imagination]. URL:http://www.intelros.ru/ subject/figures/dmitriy-zamyatin/print:page, 1,12250lokalnye-mify-modern-i-geografich eskoevoobrazhenie.html (accessed 10 September 2018)

5. Knyazeva E.N. Balans na krayu khaosa [Balance on the Edge of Chaos]. Sinergeticheskaya paradigma. Chelovek $i$ obshchestvo $v$ usloviyakh nestabilnosti [Synergetic Paradigm. Man and Society in the Conditions of Instability]. Moscow, ProgressTraditsiya Publ., 2003, pp. 139-143.

6. Lyusyy A.P. Geografiya tekstualnoy revolyutsii: mezhdistsiplinarnye issledovaniya lokalnykh tekstov kultury [Geography of the Textual Revolution: Interdisciplinary Research into Texts of Culture]. Chelovek: obraz i sushchnost, 2014, no. 1, pp. 214-236.

7. Murzina I.Ya. Regionalnaya kultura kak predmet filosofsko-kulturologicheskogo issledovaniya [Regional Culture as a Subject of Philosophical and Cultural Research]. Izvestiya Uralskogo gosudarstvennogo universiteta. Problemy obrazovaniya, nauki i kultury. Vyp. 15, 2003, no. 29, pp. 60-78.

8. Rulina T.K. Mentalnye podkhody k fasilitatsii bolshikh sotsialnykh grupp: problema bezopasnosti kollektivnogo intellekta soobshchestva [Mental Approaches to Facilitation of Large Social Groups: the Problem of Security of Collective Intelligence of the Community]. Azimut nauchnykh issledovaniy, 2015. no. 3 (12), pp. 52-55. 
B.A. Храпова, И.В. Карандашов. Региональный текст в современной социокультурной динамике

9. Flier A.Ya. Vektor kulturnoy evolyutsii [The Vector of Cultural Evolution]. Observatoriya kultury, 2011, no. 5, pp. 6-18.

10. Khrapova V.A. K voprosu o regionalnoy identichnosti [On the Issue of Regional Identity].
Vestnik Volgogradskogo gosudarstvennogo universiteta. Seriya 7, Filosofiya. Sotsiologiya $i$ sotsialnye tekhnologii [Science Journal of Volgograd State University. Philosophy. Sociology and Social Technologies], 2011, no. 2 (14), pp. 90-96.

\section{Information about the Authors}

Viktoria A. Khrapova, Doctor of Sciences (Philosophy), Associate Professor, Professor of the Department of Philosophy, Volgograd State University, Prosp. Universitetsky, 100, 400062 Volgograd, Russian Federation, khrapova@volsu.ru.

Ivan V. Karandashov, free researcher, Volgograd, Russian Federation, kiv17@gmail.com.

\section{Информация об авторах}

Виктория Анатольевна Храпова, доктор философских наук, доцент, профессор кафедры философии, Волгоградский государственный университет, просп. Университетский, 100, 400062 г. Волгоград, Российская Федерация, kyrapova@volsu.ru.

Иван Вадимович Карандашов, свободный исследователь, г. Волгоград, Российская Федерация, kiv17@gmail.com. 